\title{
Fotografias, rebuçados e histórias cantadas
}

\author{
João Carneiro
}
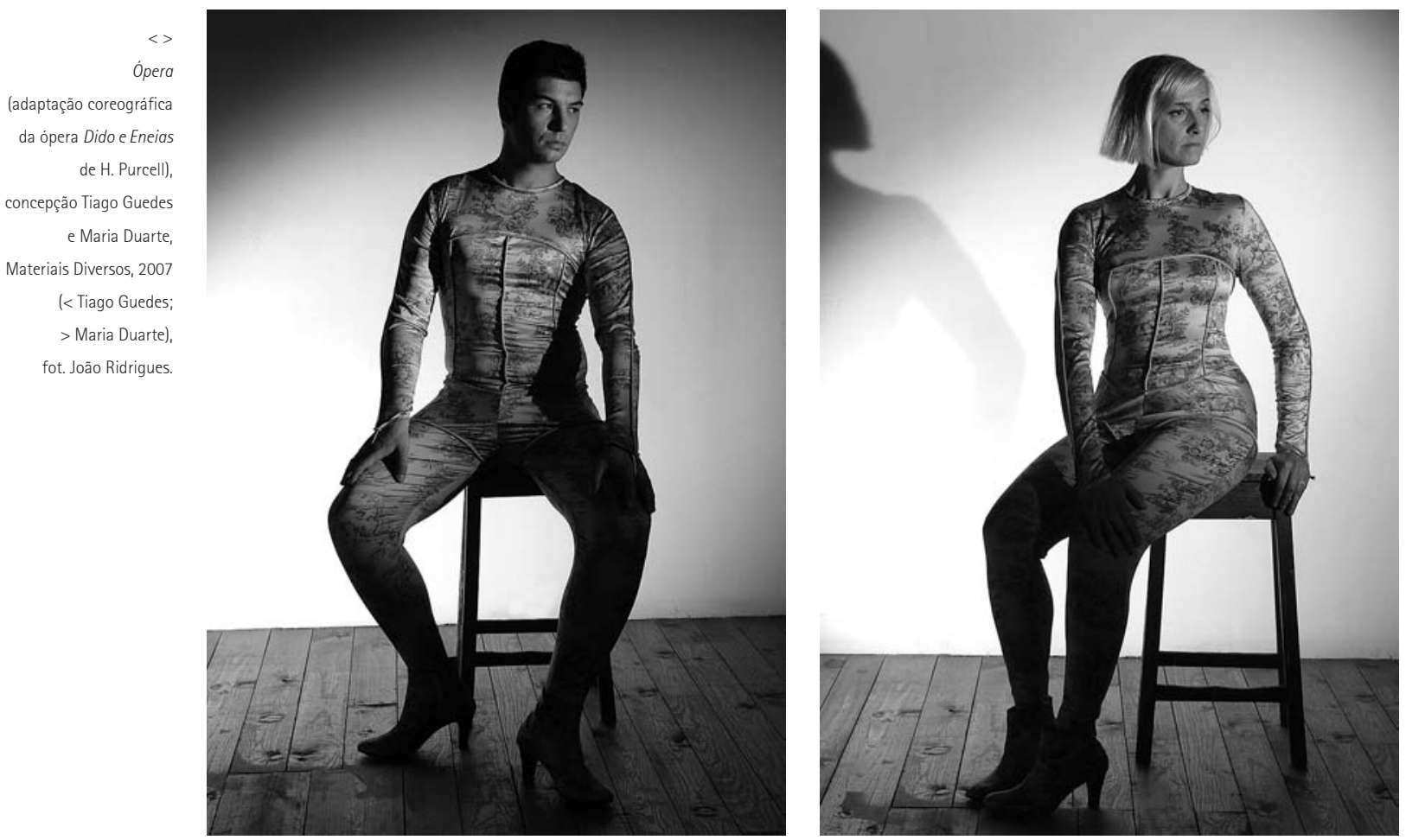

Titulo: Ópera (a partir de Dido e Eneias, de Purcell, 1689). Concepção e Interpretação: Tiago Guedes e Maria Duarte. Música: Henry Purcell. Participação Especial: Silvia Figueiredo. Assistente da direcção artistica: Pietro Romani. Acompanhamento artístico: Augusto M. Seabra. Figurinos: Aleksandar Protich. Desenho de luz: Mafalda Oliveira. Maquilhagem: Sasha para M.A.C. Adereços: André Murraças. Produção: Materiais Diversos. Co-Produção: ZDB Negócio (Portugal), Le Vivat, scène conventionnée Danse et Théâtre, Armentières (França), Théâtre de L'L, Bruxelas (Bélgica). Apoio: RE.AL. Local e data de estreia: Negócio, Lisboa, 27 de Julho de 2007.

A ópera dá a ver, como o teatro, uma acção. Diferentemente do teatro, dá a ver uma acção com música. A escuta é fundamental, ver e ouvir são indissociáveis. 0 teatro dá a ouvir a acção, no caso de haver diálogos, mas pode haver teatro sem palavras, claro; eventualmente, até sem acção, mas deixemos agora essa questão, que abre 0 campo para outras ainda, que nos arrastariam para longe do espectáculo em causa, Ópera, de Tiago Guedes e Maria Duarte.

Trata-se de um espectáculo concebido a partir da ópera Dido e Eneias, de Purcell, representada pela primeira vez em 1689. Contudo, somos logo avisados, lendo as notas do autor, corroboradas pelas notas do assessor artístico Augusto Seabra, para uma característica: "Interessou-me trabalhar não tanto (ou não só) com a musicalidade mas também o próprio processo de escuta que ela proporciona: o tipo de atenção, o estado físico e mental que propicia. Como trabalhar coreograficamente a escuta?"1

Estamos num terreno algo diferente do da encenação, mesmo do da encenação de ópera feita por coreógrafos e bailarinos. A relação dos bailarinos com a dança, com a música e com o corpo gera, com alguma razão, uma expectativa particular em relação aos trabalhos que criam para ou com a ópera. Afinal, o corpo tem sido objecto de uma relação complexa, muitas vezes difícil, no teatro ocidental, e a dança pode, muitas vezes, obrigar a rever atitudes que pareciam ter esquecido que um actor é um corpo, que a sua presença é a presença de um corpo, e que a voz, tantas vezes entendida como uma espécie de desmaterialização do corpo, deve a sua existência a esse corpo tantas vezes secundarizado pelo teatro - e tudo 


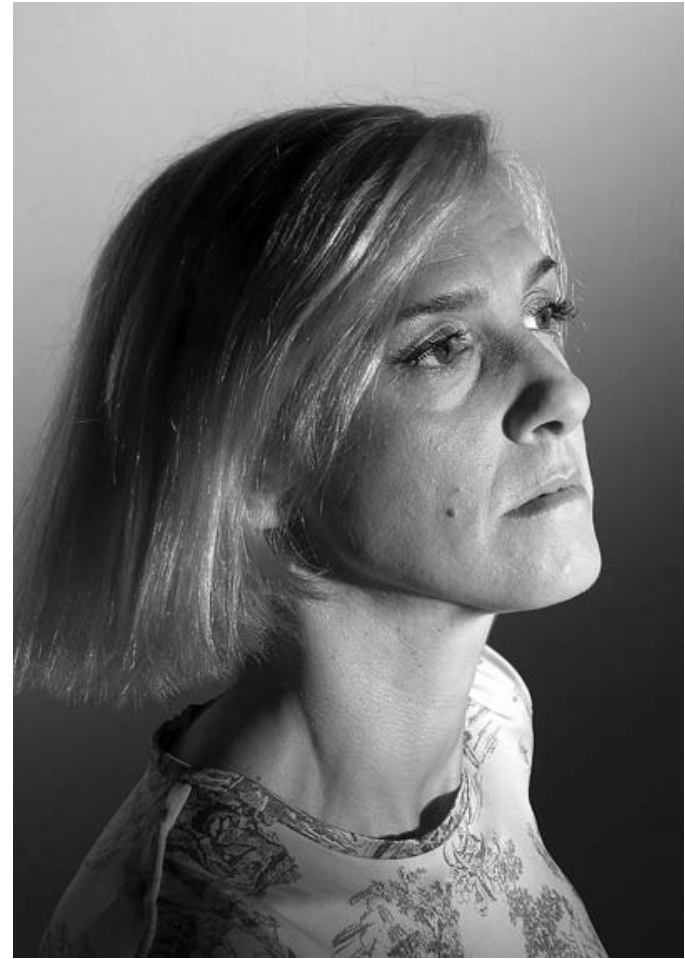

isto se pode aplicar à ópera, e à vida da ópera nos lugares em que é realizada.

Pina Bausch e Trisha Brown são duas das figuras da dança contemporânea que mais significativamente têm contribuido para uma incursão de coreógrafos na ópera, na maneira de encenar tendo em conta a relação particular do corpo, da música e da palavra, numa articulação complexa que ajuda a realizar as possibilidades de recepção, de entendimento e de construção de sentidos que, na ópera, estão em jogo. Anne Teresa de Keersmaeker é outra das figuras que, a partir da dança, tem vindo a propor modalidades de refazer a relação entre palavra, música e dança - o mesmo se poderia dizer de outros coreógrafos, como Bill T. Jones, por exemplo, mas a escolha aqui é estritamente exemplificativa e funcional, de maneira nenhuma histórica e muito menos exaustiva. 0 trabalho de Anne Teresa de Keersmaekaer aborda muito livremente os terrenos do teatro e da ópera, sem se preocupar demais com uma restituição de um objecto segundo uma determinada expectativa, como acontece com a encenação de uma peça de teatro ou de uma ópera, mas segundo uma abordagem que junta materiais diversos e propõe

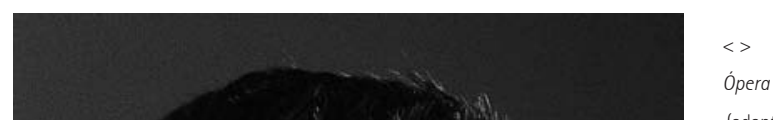

(adaptação coreográfica da ópera Dido e Eneias de H. Purcell), concepção Tiago Guedes e Maria Duarte, Materiais Diversos, 2007 (< Maria Duarte; $>$ Tiago Guedes), fot. João Ridrigues. resultados que, relativamente ao que se espera de uma encenação, são inesperados².

Este aspecto inesperado, este tipo de imprevisibilidade, faz parte da estrutura de objectos como o Lied, ou mesmo, e até certo ponto, a ópera. Trata-se, em qualquer destes dois casos, de articular palavras e música, de maneira que nenhum texto ou conjunto de palavras é o mesmo depois de ser articulado com a música - e isto, realmente, do melodrama ao Lied, do recitativo à ária. Um caso semelhante é o do movimento e da música, no qual nem um nem a outra são totalmente reconheciveis na sua autonomia depois de articulados de maneira a constituírem um todo, independentemente de qualquer exercício de análise que permita a consideração de cada elemento individualmente, e independentemente de termos em atenção o facto de a composição de muitas obras coreográficas que incluem música serem compostas independentemente da música, e de a junção dos dois elementos ser a articulação a posteriori de duas entidades inicialmente autónomas. Em Ópera, o espectáculo de Tiago Guedes e Maria Duarte, ouvimos a ópera Dido e Eneias na sua integralidade, excepto uma pequena sequência final.
2Uma listagem

relativamente completa dos espectáculos de Anne Teresa de Keersmaekar pode ser encontrada no seu livro (2002). 
Tiago Guedes e Maria Duarte - ele coreógrafo e bailarino, ela actriz - estão em cena durante todo o tempo de execução da música, que é o tempo de duração do espectáculo. Estão vestidos de igual, com um fato inteiro, de Aleksandar Protich, uma espécie de malha que cobre o corpo do pescoço até ao salto das botas. A roupa sugere, no traço do figurino e nos desenhos do tecido, cenas e motivos florais em tons de castanho dourado, o universo decorativo do barroco ou do rocócó - e, por associação, de uma forma muito lata, um período marcado, também, por uma estilização particular da representação teatral e de ópera. É este universo estilístico, entre a dança e a representação, que guia a construção coreográfica do espectáculo, económico nos seus movimentos, que por sua vez sugerem, muito mais do que reproduzem exactamente, o universo a que se referem. É um universo que, na sua recriação, em Ópera, é gerido por uma grande economia de gestos, por uma ênfase na pose que evita o pathos, por uma ostensão que seria simbólica, ou demasiado simbólica para ser realmente eficaz, se não fosse investida de um forte e consciente artificialismo, de uma consciência do acto de dar a ver coisas que foram feitas há muito tempo mas são, ou podem ser, revisitadas, refeitas - ou ressuscitadas - periodicamente.

É neste ponto, o da consciência do artifício que preside à feitura dos materiais - a ópera, a execução - que é particularmente relevante o facto de os dois intérpretes interpretarem integralmente, em playback, todas as personagens da ópera, com excepção dos coros: Dido e Eneieas, a rainha e o herói, apaixonados e posteriormente condenados a separar-se; Belinda, a confidente da rainha; as feiticeiras. Os intérpretes do espectáculo não organizam materiais como numa encenação, em que outros representam e cantam. Eles representam, mexem-se, e apropriam-se de um aspecto essencial da ópera, o canto, recorrendo à mímica, naquilo que é uma dos artifícios maiores e mais perturbantes, na sua ostensiva maneira de se mostrar falso, cópia, reprodução e impossibilidade de pensar que estamos perante um qualquer original. 0 playback, essa imitação muda da voz, é o original de si próprio, e nunca como neste espectáculo. A verdadeira paródia deforma o seu modelo para o subverter e, simultaneamente, Ihe prestar homenagem, ou para afirmar a sua dependência face ao original que toma como ponto de partida. Ópera não chega a deformar nem a subverter o seu modelo, antes the presta homenagem, refazendo mentirosamente aquilo que Ihe é essencial, a voz, que neste caso é a dos cantores de uma gravação disponivel comercialmente. Este aspecto é determinante para a originalidade do espectáculo, e permite ouvir a ópera de uma maneira que, acrescendo ao trabalho dos primeiros intérpretes, cronologicamente - os cantores e os músicos da gravação - cria, a partir da espacialização e do movimento global proposto em cena, uma nova escuta, ou pelo menos uma escuta diferente. Como as marionetas, que representam um corpo real a partir da ostensão do carácter artificial da representação e assim refazem possibilidades de entendimento da representação e do representado, também Ópera possibilita um entendimento original de um objecto substituindo um traço fundamental desse objecto - a presença física de cantores - por uma representação desse traço. Neste caso, essa representação, sendo uma cópia deflacionada do original, acentua aquilo que na cópia falta, e que está presente apenas em som. A consciência de uma perda é modificada pela consciência do que se passa no processo em que se dissociam coisas que habitualmente estão associadas - corpo e voz, por exemplo - e que, em vez de se propor refazer o objecto original, o restitui sob uma forma diferente. Finalmente, a economia de meios e a simplicidade aparente da proposta, refazem para o espectador o carácter imediato de uma relação que a ópera, nos seus melhores momentos, proporciona. De tal modo que, num dos interlúdios orquestrais, é perfeitamente possivel divertirmo-nos, inocentemente como todo o verdadeiro prazer, com a rapariga (Silvia Figueiredo) que vende fotografias autografadas dos intérpretes, e distribui rebuçados gratuitamente, enquanto trauteia - realmente, com voz - a música que vai continuando a ouvir-se. Podemos levar para casa as caras e os corpos dos verdadeiros artistas, em papel, enquanto os drops se derretem, realmente, sem deixar outras marcas a não ser um leve sabor na língua, e traços de açúcar no sangue, detectáveis, eventualmente, num hemograma.

\section{Referência bibliográfica}

KEERSMAEKER, Anne Teresa de (2002), Rosas, Tournai, Bruxelas, La Renaissance du Livre. 